\title{
Role of prostaglandins in intrauterine migration of the equine conceptus
}

\author{
T. A. E. Stout* and W. R. Allen \\ University of Cambridge Equine Fertility Unit, Mertoun Paddocks, Woodditton Road, \\ Newmarket, Suffolk CB8 9BH, UK
}

Between at least day 9 and day 16 after ovulation the spherical equine conceptus migrates continuously throughout the uterine lumen, propelled by peristaltic myometrial contractions. This unusually long period of intrauterine movement ensures that the conceptus delivers its antiluteolytic signal to the entire endometrium to achieve luteostasis. The present experiment tested the hypothesis that prostaglandins stimulate the myometrial contractions that result in the migration of the conceptus. Serial ultrasonographic examinations of the uteri of eight mares performed during $2 \mathrm{~h}$ periods between day 10 and day 18

\section{Introduction}

Intrauterine mobility of the conceptus is a remarkable feature of equine pregnancy, not least because it occurs over a substantially longer period (at least 8 days) than has been observed in any other eutherian species (Ginther, 1985). Furthermore, because there is usually only one conceptus present in the uterus of the monovulating mare, the function of this mobility is not simply to facilitate spacing of the embryos, as occurs in the multitoccus pig and in rodents (Pope et al., 1982a,b). The eventual cessation of movement of the conceptus on day 16 or day 17 after ovulation is the result of a combination of its continued rapid increase in diameter and a marked increase in uterine tone, which cause the vesicle to lodge at the base of one of the uterine horns (Ginther, 1983a,b). Conceptus mobility is at a maximum between day 11 and day 14 (Leith and Ginther, 1984), presumably to ensure distribution of the embryonic anti-luteolytic signal to the entire surface of the endometrium and thereby suppress cyclical release of $\mathrm{PGF}_{2 \alpha}$ from the endometrium and achieve the luteostasis necessary for maintenance of pregnancy (McDowell et al., 1985). In this respect, the mobility of the equine conceptus is analogous to the marked elongation of the trophoblast which parallels the maternal recognition of pregnancy in

*Current address: Utrecht University, Department of Equine Sciences, Section Reproduction, Yalelaan 12, 3584 CM Utrecht, The Netherlands

Email: T.A.E.Stout@vet.uu.nl of gestation recorded the pattern of conceptus migration before and after treatment with the cyclo-oxygenase inhibitor flunixin meglumine. Conceptus mobility was high between day 10 and day 14 after ovulation $(4.3 \pm 0.8$, $4.7 \pm 0.8$ and $4.3 \pm 0.9$ changes of location per $h$ on day 10, day 12 and day 14, respectively), but was reduced immediately and markedly by an i.v. injection of flunixin meglumine $(3.8 \pm 1.5,1.8 \pm 0.8$ and $0.7 \pm 0.2$ location changes per $h$ ), thereby implicating prostaglandins as the primary stimulus for the myometrial contractions that drive migration of the conceptus.

other domestic ungulate species (Amoroso, 1952), but is so characteristically absent during pregnancy in horses.

Although the precise stimulus for migration of the equine conceptus is unknown, it is apparent that localized myometrial contractions provide the driving force that literally squeezes the vesicle around the uterine lumen (Ginther, 1984; Cross and Ginther, 1988). Furthermore, because twin conceptuses migrate independently of each other, Ginther (1985) suggested that the conceptus itself might stimulate the myometrial contractions that move it around the uterus. The discovery that equine embryos secrete $\mathrm{PGE}_{2}$ from as early as day 5 after ovulation when they are still in the oviduct (Weber et al., 1991a), and that $\mathrm{PGE}_{2}$ relaxes the smooth muscle of the isthmus to permit onward passage of the embryo into the uterus (Weber et al., 1991b, 1995), has rekindled interest in the scale and possible purpose of prostaglandin production by the preimplantation equine conceptus. Once in the uterus, the blastocyst continues to secrete both $\mathrm{PGE}_{2}$ (Watson and Sertich, 1989; Weber et al., 1992; Vanderwall et al., 1993a) and PGF $_{2 \alpha}$ (Watson and Sertich, 1989) and, because these two prostaglandins are known to have potent actions on smooth muscle activity in a number of body systems, it is possible that prostaglandins secreted by the conceptus stimulate the myometrium as they have been shown to do when administered exogenously (Taverne et al., 1979; Jones et al., 1991; Troedesson et al., 1995).

In the present experiment, the role of prostaglandins in the transuterine migration of the equine blastocyst was investigated by administering a cyclo-oxygenase inhibitor to mares between day 10 and day 18 of gestation. 


\section{Materials and Methods}

\section{Animals}

Pregnancy was diagnosed in eight Thoroughbred mares by transrectal ultrasonographic examination of their uteri on day 10 or, if the vesicle could not be detected at this stage, on day 12 after ovulation. At 2 day intervals, from the time the conceptus was first detected until day 18 after ovulation, the uterus of each mare was palpated and scanned, and a $2 \mathrm{~h}$ conceptus mobility trial was performed. Uterine tone was assessed and rated subjectively on a scale of 0 to 4 , and the diameter of the conceptus was measured in two dimensions.

\section{Conceptus mobility trial}

Each conceptus mobility trial consisted of 25 ultrasonographic determinations of the position of the conceptus within the uterine lumen, performed at 5 min intervals over $2 \mathrm{~h}$. The uterus was divided nominally into nine segments as described by Leith and Ginther (1984) and these included the cranial, middle and caudal portions of the body, and each uterine horn. Throughout the $2 \mathrm{~h}$ scanning period the mares were restrained unsedated in stocks in pairs and fed ad libitum.

\section{Treatment schedules}

The eight mares were assigned randomly to one of two experimental groups. In the first group (group A), five mares were given an i.v. injection of flunixin meglumine (Finadyne; Schering Plough, Cambs), administered at the normal therapeutic dose of $1.1 \mathrm{mg} \mathrm{kg}^{-1}$, in the middle of each $2 \mathrm{~h}$ mobility trial and therefore on alternate days. The three mares in the second group (Group B) were used as controls and were not treated with the cyclo-oxygenase inhibitor before or during the examinations. However, to eliminate the possibility that venepuncture might affect conceptus mobility, the control mares were injected with an appropriate volume of sterile water in the middle of the $2 \mathrm{~h}$ scanning protocol.

One control mare showed mild haemorrhage from the rectal mucosa towards the end of the 14 day examination period and was therefore withdrawn from further examinations. Peripheral serum samples were collected each day from individual mares and assayed for their progesterone concentrations to establish whether treatment affected luteal function.

\section{Progesterone assay}

Progesterone concentrations in unextracted serum were measured using an amplified enzyme linked immunoassay (AELIA: Dako Diagnostics, Cambs), validated for horse serum by Allen and Sanderson (1987), which used an antiprogesterone monoclonal antibody coated on to the surface of the wells of a microtitre plate. The assay showed a limit of sensitivity of $0.135 \mathrm{ng} \mathrm{ml}^{-1}$ and intra- and interassay coefficients of variation of 6 and $8 \%$, respectively.

\section{Statistical analyses}

Conceptus mobility was quantified in two ways. Firstly, by the number of times a vesicle had moved to a different segment between consecutive determinations and, secondly, by the number of uterine segments traversed during these location changes. Two-factor ANOVAs were used to determine whether treatment with flunixin meglumine or the stage of gestation had any significant effects on either of these indices of conceptus migration. In particular, conceptus movement after flunixin meglumine treatment was compared with that recorded during both the $1 \mathrm{~h}$ pre-treatment period and with that in the control mares during the $1 \mathrm{~h}$ period after the injection of sterile water. When differences were observed, the effect of treatment at the different stages of gestation studied was analysed further using one-way ANOVA.

\section{Results}

In all mares, conceptus mobility was at a maximum between day 10 and day 14 after ovulation, and decreased sharply as conceptus fixation intervened $(P=0.0012$; Table 1 ) so that, by day 18 , the conceptus was stationary at the base of one of the uterine horns. Conceptus mobility decreased significantly after the administration of flunixin meglumine (group A), both in terms of the total number of times the conceptus altered its position $(P<0.001)$ and the total number of uterine segments it traversed $(P<0.001$; Table 1), but not after administration of control sterile water (group B). This inhibition of movement occurred immediately after treatment and was most apparent on day 12 and day 14 after ovulation, at which time conceptus mobility in the control mares (group B) remained high (Table 1). Fixation of the conceptus from day 16 onwards was clearly the result of the coincidental and significant increases in the diameter of the conceptus $(P=0.002)$ and in uterine tone $(P<0.0002)$ that were noted during the experimental period. More specifically, the rate of expansion of the conceptus was maximum between day 10 and day 16 after ovulation, with little additional increase in diameter between day 16 and day 18 (Table 2), whereas uterine tone increased steadily during the observation period until day 18 when it reached the intensity characteristic of pregnancy (Table 3). Administration of flunixin meglumine on alternate days had no discernible effects on the expansion of the conceptus (Table 2), uterine tone (Table 3) or serum progesterone profiles (Fig. 1).

\section{Discussion}

The present experiment was designed to test the hypothesis that, between day 10 and day 16 after ovulation in the mare, prostaglandins influence myometrial smooth muscle activity in a manner that propels the conceptus around the uterus. This hypothesis was supported by the immediate and marked decrease in conceptus mobility after i.v. 
Table 1. Mean conceptus mobility scores measured using ultrasonography in mares between day 10 and day 18 of gestation, before and after treatment with the cyclo-oxygenase inhibitor flunixin meglumine

\begin{tabular}{|c|c|c|c|c|}
\hline \multirow[b]{2}{*}{$\begin{array}{l}\text { Stage of gestation } \\
\text { (days) }\end{array}$} & \multicolumn{2}{|c|}{ Flunixin meglumine $(n=5)$} & \multicolumn{2}{|c|}{ Controls $(n=3)$} \\
\hline & $\begin{array}{l}\text { Before treatment } \\
\qquad(1 \mathrm{~h})^{*}\end{array}$ & $\begin{array}{l}\text { After treatment } \\
\qquad(1 \mathrm{~h})^{*}\end{array}$ & $\begin{array}{l}\text { Before treatment } \\
\qquad(1 \mathrm{~h})^{*}\end{array}$ & $\begin{array}{l}\text { After treatment } \\
\qquad(1 \mathrm{~h})^{*}\end{array}$ \\
\hline 10 & $\begin{array}{c}4.3 \pm 0.8 \\
(5.2 \pm 1.2)\end{array}$ & $3.8 \pm 1.5$ & 4.0 & 4.0 \\
\hline 12 & $\begin{array}{r}4.7 \pm 0.8^{\mathrm{a}} \\
(5.3 \pm 1.3)\end{array}$ & $1.8 \pm 0.8^{b}$ & $3.7 \pm 1.3^{\mathrm{a}}$ & $\begin{array}{l}4.0 \pm 1.0^{\mathrm{a}} \\
(6.0 \pm 2.1)\end{array}$ \\
\hline 14 & $\begin{array}{r}4.3 \pm 0.9^{a} \\
(4.8 \pm 1.2)\end{array}$ & $0.7 \pm 0.2^{b}$ & $3.0 \pm 1.0^{\mathrm{a}}$ & $4.0 \pm 0.6^{\mathrm{a}}$ \\
\hline 16 & $0.5 \pm 0.5$ & $0.0 \pm 0.0$ & $1.5 \pm 0.5$ & $2.0 \pm 2.0$ \\
\hline 18 & 0.0 & 0.0 & 0.0 & 0.0 \\
\hline
\end{tabular}

*Duration of ultrasonography.

Values expressed as the mean \pm SEM number of times a conceptus moved from one of nine uterine segments to another.

Values in parentheses represent the mean \pm SEM number of segments traversed during migration when this differed from the figure above.

Within a row, values with different superscripts differ significantly $(P<0.001)$.

administration of the cyclo-oxygenase inhibitor flunixin meglumine, particularly on day 12 and day 14 after ovulation. The timing of flunixin meglumine administration (that is mid-way through the mobility trial) was chosen to coincide with the period when plasma concentrations of the compound would be at a maximum and also to allow continuity of monitoring before and after treatment. Experimental studies had demonstrated that, at the dose rate of flunixin meglumine used, systemic eicosanoid concentrations started to decrease within 10 min of the i.v. injection and that the inhibitory effects started to decrease only after about $4 \mathrm{~h}$ (Semrad et al., 1985). Similarly, intravenous administration of flunixin meglumine rapidly blocked the prostaglandin release response to either endotoxin administration (< 5 min; Templeton et al., 1987) or uterine manipulation (<15 min; Berglund et al., 1982) and, therefore, it was apparent that inhibition of de novo prostaglandin release begins very soon after administration of this inhibitor.

Although the pronounced inhibitory action of flunixin meglumine on conceptus movement demonstrated a definitive role for prostaglandins in the mobility process, it was not possible to discriminate between prostaglandins secreted by the conceptus and those that may have been produced by the endometrium or some other maternal tissue, as the main propulsive force for the conceptus. The equine conceptus is capable of substantial prostaglandin synthesis (Watson and Sertich, 1989; Weber et al., 1992) and since flunixin meglumine inhibits secretion of conceptus prostaglandin in vitro (Stout and Allen, 1996), it would presumably do so in vivo provided that the drug reached the uterine lumen in sufficient quantities. Indeed, there is a precedent for the inhibition of conceptus prostaglandin production in vivo by systemically administered flunixin meglumine: Geisert et al. (1986) demonstrated that parenteral administration of flunixin meglumine or indomethacin to pregnant sows suppressed the pregnancy-
Table 2. Mean ( \pm SEM) conceptus diameters $(\mathrm{mm})$ measured using ultrasonography in mares treated with the cyclo-oxygenase inhibitor flunixin meglumine between day 10 and day 18 after ovulation

\begin{tabular}{lcc}
\hline $\begin{array}{l}\text { Stage of gestation } \\
\text { (days) }\end{array}$ & $\begin{array}{c}\text { Flunixin meglumine } \\
(n=5)\end{array}$ & $\begin{array}{c}\text { Controls } \\
(n=3)\end{array}$ \\
\hline 10 & $2.0 \pm 0.3$ & 0.0 \\
12 & $11.4 \pm 0.6$ & $10.5 \pm 2.3$ \\
14 & $22.1 \pm 0.7$ & $19.8 \pm 2.4$ \\
16 & $30.7 \pm 1.6$ & $32.0 \pm 0.5$ \\
18 & $31.0 \pm 3.3$ & $28.5 \pm 1.0$ \\
\hline
\end{tabular}

Flunixin meglumine was administered on alternate days.

Table 3. Mean ( \pm SEM) uterine tone scores measured in pregnant mares treated with the cyclo-oxygenase inhibitor flunixin meglumine between day 10 and day 18 after ovulation

\begin{tabular}{lcc}
\hline $\begin{array}{l}\text { Stage of gestation } \\
\text { (days) }\end{array}$ & $\begin{array}{c}\text { Flunixin meglumine } \\
(n=5)\end{array}$ & $\begin{array}{c}\text { Controls } \\
(n=3)\end{array}$ \\
\hline 10 & $1.7 \pm 0.1$ & - \\
12 & $2.3 \pm 0.2$ & $2.3 \pm 0.1$ \\
14 & $2.9 \pm 0.1$ & $2.8 \pm 0.4$ \\
16 & $3.5 \pm 0.1$ & $3.4 \pm 0.1$ \\
18 & $3.6 \pm 0.1$ & $3.9 \pm 0.1$ \\
\hline
\end{tabular}

Uterine tone was scored subjectively on a scale of 0 to $4(0=$ flaccid; 4 = intensely tonic) and did not differ significantly between treated and control mares.

Flunixin meglumine was administered on alternate days.

dependent increase in uterine luminal $\mathrm{PGF}_{2 \alpha}$ concentrations that occurs on day 12 after ovulation, and is thought to be a function of increased production by the rapidly expanding blastocysts.

The alternative possibility is that the prostaglandins responsible for conceptus mobility are secreted by the 


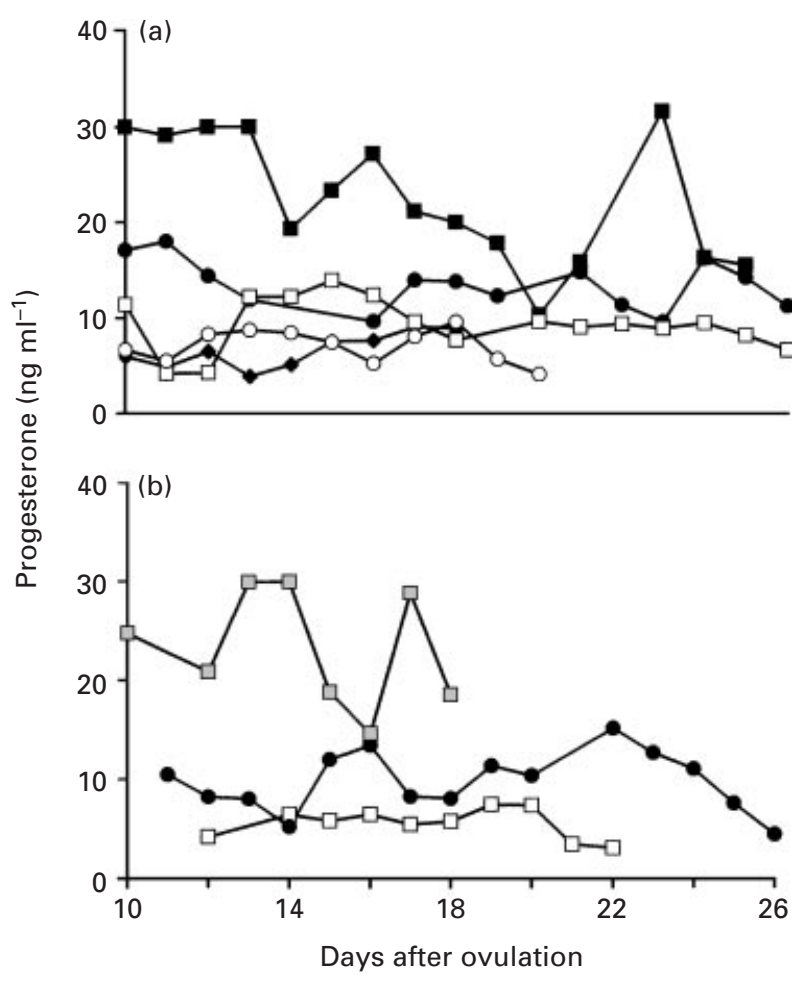

Fig. 1. Peripheral serum progesterone concentrations measured during day 10 and day 26 after ovulation in pregnant mares treated on alternate days with (a) flunixin meglumine $(n=5)$ and (b) control sterile water $(n=3)$. Symbols represent data for individual mares.

endometrium. However, uterine luminal $\mathrm{PGF}_{2 \alpha}$ concentrations remain low during the period of conceptus mobility (Zavy et al., 1978; Berglund et al., 1982; Stout and Allen, 1998) and concentrations of $\mathrm{PGF}_{2 \alpha}$ and its metabolites in the uterine vein (Douglas and Ginther, 1976) and systemic circulation (Kindahl et al., 1982) are also at basal values during this period. Although there is some evidence of endometrial $\mathrm{PGE}_{2}$ secretion during the phase of conceptus mobility, $\mathrm{PGE}_{2}$ concentrations in uterine luminal flushings (Watson and Sertich, 1989; Stout and Allen, 1998) do not differ between day 14 and day 18 pregnant and cyclic mares, whereas uterine contractility differs markedly between these two groups (Cross and Ginther, 1988). Even if the equine uterus is not a source of large quantities of prostaglandins during early pregnancy, the possibility remains that the endometrium immediately adjacent to the conceptus could secrete prostaglandins in quantities sufficient to stimulate local myometrial activity, without increasing the intrauterine or systemic concentrations of the hormones. In this respect, a mechanism may be present by which the conceptus might induce such localized endometrial prostaglandin release. Namely, its secretion of significant quantities of oestrogens from as early as day 10 after ovulation (Zavy et al., 1979; Heap et al., 1982; Stout and Allen, 1996), coupled with the demonstration that oestrogens can stimulate increased $\mathrm{PGF}_{2 \alpha}$ secretion by equine endometrium, both in vitro (Vernon et al., 1981) and in vivo (Goff et al., 1993).

Vanderwall et al. (1993b) concluded that $\mathrm{PGE}_{2}$ produced by the conceptus was unlikely to be the product that stimulated movement of the conceptus when they found that saline-filled simulated conceptus vesicles inserted into the uterine lumen of cyclic or pregnant mares were moved around the uterus just as readily as $\mathrm{PGE}_{2}$-filled vesicles. However, these authors also noted that, although salinefilled vesicles inserted into the uteri of pregnant mares were no less mobile than the indigenous conceptus, both were considerably less mobile than the same conceptus had been before the vesicle was inserted. Thus, it seems likely that the act of inserting a vesicle into the uterus interfered with the normal patterns of uterine contractions and thereby confounded the results.

In contrast, Gastal et al. (1998a) reported that the intrauterine administration of $\mathrm{PGE}_{2}$ increased uterine tone and contractility, which is consistent with the contention that $\mathrm{PGE}_{2}$ plays a role in conceptus mobility. In a subsequent experiment, Gastal et al. (1998b) failed to increase the rate of conceptus migration by administering $\mathrm{PGF}_{2 \alpha}$ systemically to day 12 pregnant mares and concluded that $\mathrm{PGF}_{2 \alpha}$ is unlikely to be involved in conceptus movement. However, the approach used by Gastal et al. (1998b) did not consider the possibility that prostaglandins secreted by the conceptus have a localized action so that parenteral stimulation of the whole uterus is unlikely to be an appropriate model. Furthermore, both Gastal et al. (1998a,b) and Vanderwall et al. (1993b) used only one prostaglandin in isolation, $\mathrm{PGF}_{2 \alpha}$ or $\mathrm{PGE}_{2}$, whereas it is likely that progression of the conceptus depends on a balance in the release of both of these molecules, and possibly other prostanoids.

In conclusion, it is proposed that prostaglandins secreted either by the conceptus or by the endometrium abutting the conceptus, possibly under the influence of a signal from the conceptus, play a pivotal role in stimulating the peristaltic myometrial contractions that propel the conceptus around the uterus and thereby enable it to distribute its antiluteolytic signal to the whole endometrium. However, the identity of this signal, which enables maternal recognition of pregnancy, remains unknown.

This work was funded by the Horserace Betting Levy Board (via a Veterinary Research Training Scholarship), the Thoroughbred Breeders Association of Great Britain and the Dorothy Russel Havemeyer Foundation of New York. The authors are grateful to C. Brown for performing the progesterone assays, and to C. Towers and $\mathrm{M}$. Jones for assisting with the management and examinations of the experimental mares.

\section{References}

Allen WR and Sanderson MW (1987) The value of a rapid progesterone assay (AELIA) in equine stud veterinary medicine and management Proceedings of the Ninth Bain-Fallon Memorial Lectures pp 75-82 Ed. P Huntington. AEVA, Sydney 
Amoroso EC (1952) Placentation. In Marshall's Physiology of Reproduction Vol. 2 3rd Edn pp 127-311 Ed. AS Parkes. Longmans Green, London

Berglund L-A, Sharp DC, Vernon MW and Thatcher WW (1982) Effect of pregnancy and collection technique on prostaglandin $\mathrm{F}$ in the uterine lumen of pony mares Journal of Reproduction and Fertility Supplement $32335-341$

Cross DT and Ginther OJ (1988) Uterine contractions in non-pregnant and early pregnant mares and jennies as determined by ultrasonography Journal of Animal Science $\mathbf{6 6}$ 250-254

Douglas RH and Ginther OJ (1976) Concentration of prostaglandin F in uterine venous plasma of anaesthetised mares during the oestrous cycle and early pregnancy Prostaglandins 11 251-260

Gastal MO, Gastal EL, Torres CAA and Ginther OJ (1998a) Effect of oxytocin, prostaglandin $F_{2 \alpha}$ and clenbuterol on uterine dynamics in mares Theriogenology 50 521-534

Gastal MO, Gastal EL, Torres CAA and Ginther OJ (1998b) Effect of PGE on uterine contractility and tone in mares Theriogenology 50 989-999

Geisert RD, Rasby RJ, Minton JE and Wetteman RP (1986) Role of prostaglandins in development of porcine blastocysts Prostaglandins $\mathbf{3 1}$ 191-204

Ginther OJ (1983a) Mobility of the early equine conceptus Theriogenology 19 603-611

Ginther OJ (1983b) Fixation and orientation of the early equine conceptus Theriogenology 19 613-623

Ginther OJ (1984) Intrauterine movement of the early conceptus in barren and postpartum mares Theriogenology 21 633-644

Ginther OJ (1985) Dynamic physical interactions between the equine embryo and uterus Equine Veterinary Journal Supplement 3 41-47

Goff AK, Sirois J and Pontbriand D (1993) Effect of oestradiol on oxytocinstimulated prostaglandin $\mathrm{F}_{2 \alpha}$ release in mares Journal of Reproduction and Fertility 98 107-112

Heap RB, Hamon M and Allen WR (1982) Studies on oestrogen synthesis by the preimplantation equine conceptus Journal of Reproduction and Fertility Supplement 32 343-352

Jones DM, Fielden ED and Carr DH (1991) Some physiological and pharmacological factors affecting uterine motility as measured by electromyography in the mare Journal of Reproduction and Fertility Supplement 44 357-368

Kindahl H, Knudsen O, Madej A and Edqvist L-E (1982) Progesterone, prostaglandin $\mathrm{F}_{2 \alpha,}$ PMSG and oestrone sulphate during early pregnancy in the mare Journal of Reproduction and Fertility Supplement 32 353-359

Leith GS and Ginther OJ (1984) Characterisation of intrauterine mobility of the early equine conceptus Theriogenology 22 401-408

McDowell KJ, Sharp DC, Peck LS and Cheves LL (1985) Effect of restricted conceptus mobility on maternal recognition of pregnancy in mares Equine Veterinary Journal Supplement 3 23-24

Pope WF, Maurer RR and Stormshak F (1982a) Intrauterine migration of the porcine embryo: influence of estradiol-17 $\beta$ and histamine Biology of Reproduction 27 575-579

Pope WF, Maurer RR and Stormshak F (1982b) Intrauterine migration of the porcine embryo. Interaction of embryo, uterine flushings and indomethacin on myometrial function in vitro. Journal of Animal Science 55 1169-1178

Semrad SD, Hardee GE, Hardee MM and Moore JN (1985) Flunixin meglumine given in small doses: pharmacokinetics and prostaglandin inhibition in healthy horses American Journal of Veterinary Research $\mathbf{4 6}$ 2474-2479

Stout TAE (1998) Maternal Recognition of Pregnancy in the Mare PhD Thesis, University of Cambridge
Stout TAE and Allen WR (1996) Conceptus factors involved in the maternal recognition of pregnancy in the mare Journal of Reproduction and Fertility Abstract Series 1753

Stout TAE and Allen WR (1998) Uterine lumenal prostaglandin concentrations during late dioestrus and early pregnancy in the mare Journal of Reproduction and Fertility Abstract Series 2245

Taverne MAM, Van der Weyden GC, Fontijne P, Dielman SJ, Pashen RL and Allen WR (1979) In vivo myometrial electrical activity in the cycling mare Journal of Reproduction and Fertility 56 521-532

Templeton CB, Bottoms GD, Fessler JF, Ewert KM, Roesel OF, Johnson MA and Latshaw HS (1987) Endotoxin-induced haemodynamic and prostaglandin changes in ponies: effects of flunixin meglumine, dexamethasone and prednisolone Circulatory Shock 23 231-240

Troedsson MHT, Liu IKM, Ing M and Pascoe J (1995) Smooth muscle electrical activity in the oviduct, and the effect of oxytocin, prostaglandin $\mathrm{F}_{2 \alpha}$ and prostaglandin $\mathrm{E}_{2}$ on the myometrium and the oviduct of the cycling mare Biology of Reproduction Monograph Series 1475-488

Vanderwall DJ, Woods GL, Weber JA and Lichtenwalner AB (1993a) $\mathrm{PGE}_{2}$ secretion by the conceptus and binding by non-pregnant endometrium in the horse Equine Veterinary Journal Supplement 15 24-27

Vanderwall DK, Woods GL, Weber JA and Lichtenwalner AB (1993b) Uterine transport of prostaglandin $\mathrm{E}_{2}$-releasing simulated embryonic vesicles in mares Theriogenology $\mathbf{4 0} 13-20$

Vernon MW, Zavy MT, Asquith RL and Sharp DC (1981) Prostaglandin $F_{2 \alpha}$ in the equine endometrium, steroid modulation and production capacities during the estrous cycle and early pregnancy Biology of Reproduction 25 581-589

Watson ED and Sertich PL (1989) Prostaglandin production by horse embryos and the effect of co-culture of embryos with endometrium from pregnant mares Journal of Reproduction and Fertility 87 331-336

Weber JA, Freeman DA, Vanderwall DK and Woods GL (1991a) Prostaglandin $\mathrm{E}_{2}$ secretion by oviductal transport-stage equine embryos Biology of Reproduction 45 540-543

Weber JA, Freeman DA, Vanderwall DK and Woods GL (1991b) Prostaglandin $\mathrm{E}_{2}$ hastens oviductal transport of equine embryos Biology of Reproduction 45 544-546

Weber JA, Woods GL, Freeman DA and Vanderwall DK (1992) Prostaglandin $E_{2}$ secretion by day 6 to day 9 equine embryos Prostaglandins 43 55-59

Weber JA, Woods GL and Lichtenwalner AB (1995) Relaxatory effect of prostaglandin $E_{2}$ on circular smooth muscle isolated from the equine oviductal isthmus Biology of Reproduction Monograph Series $\mathbf{1}$ $125-130$

Zavy MT, Bazer FW, Sharp DC, Frank M and Thatcher WW (1978) Uterine luminal prostaglandin F in cycling mares Prostaglandins 16 643-649

Zavy MT, Mayer R, Vernon MW, Bazer FW and Sharp DC (1979) An investigation of the uterine luminal environment of non-pregnant and pregnant pony mares Journal of Reproduction and Fertility Supplement 27 403-411

Manuscript received 25 July 2000.

First decision 20 September 2000.

Resubmitted 19 January 2001.

Accepted 22 January 2001. 